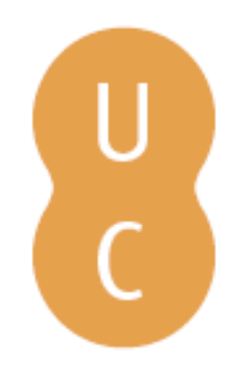

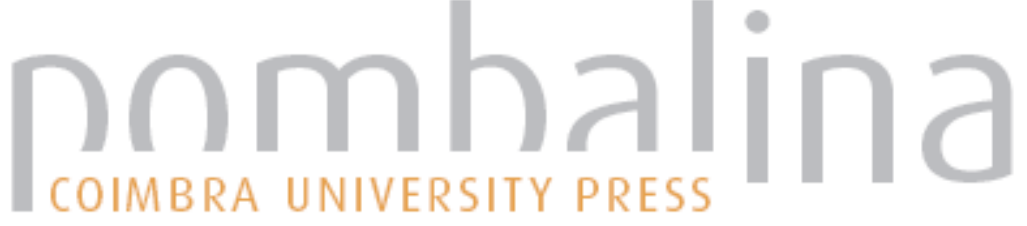

\section{Fermat e a polémica em torno da óptica}

Autor(es): $\quad$ Fitas, Augusto José dos Santos

Publicado por: Imprensa da Universidade de Coimbra

URL

persistente: $\quad$ URI:http://hdl.handle.net/10316.2/31304

DOI: $\quad$ DOI:http://dx.doi.org/10.14195/978-989-26-0241-7_4

Accessed : $\quad$ 26-Apr-2023 10:21:18

A navegação consulta e descarregamento dos títulos inseridos nas Bibliotecas Digitais UC Digitalis, UC Pombalina e UC Impactum, pressupõem a aceitação plena e sem reservas dos Termos e Condições de Uso destas Bibliotecas Digitais, disponíveis em https://digitalis.uc.pt/pt-pt/termos.

Conforme exposto nos referidos Termos e Condições de Uso, o descarregamento de títulos de acesso restrito requer uma licença válida de autorização devendo o utilizador aceder ao(s) documento(s) a partir de um endereço de IP da instituição detentora da supramencionada licença.

Ao utilizador é apenas permitido o descarregamento para uso pessoal, pelo que o emprego do(s) título(s) descarregado(s) para outro fim, designadamente comercial, carece de autorização do respetivo autor ou editor da obra.

Na medida em que todas as obras da UC Digitalis se encontram protegidas pelo Código do Direito de Autor e Direitos Conexos e demais legislação aplicável, toda a cópia, parcial ou total, deste documento, nos casos em que é legalmente admitida, deverá conter ou fazer-se acompanhar por este aviso.

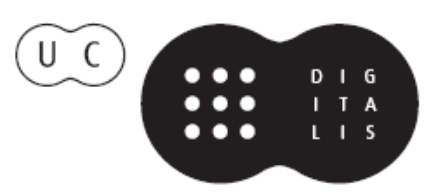




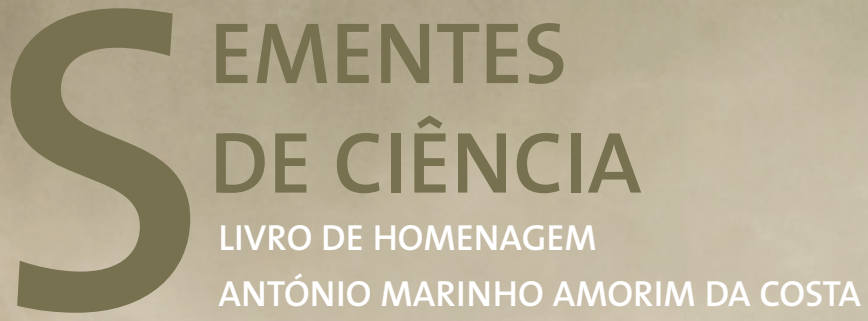

Sebastião J. Formosinho Hugh D. Burrows EDITORES 
Professor Associado com Agregação - Departamento de Física, Universidade de Évora e investigador do Centro de Estudos de História e Filosofia da Ciência (CEHFCi). e-mail: afitas@uevora.pt / página electrónica: http://evunix.uevora.pt/ afitas/

IV.

\section{FERMAT E A POLÉMICA EM TORNO DA ÓPTICA}

\section{Introdução e uma explicação}

Escreveu Max Planck (1858-1947):

"Desde sempre, e até sempre, o objectivo maior a que a Física aspira é à resolução daquele problema que abarque todos os fenómenos naturais, os já observados e os que ainda estão por observar, à custa de um Princípio simples que satisfaça todos as necessidades de cálculo. Acontece que, pela natureza das coisas, este propósito não foi nem será alcançado. Contudo, é possível estar cada vez mais próximo deste objectivo e a história da Física Teórica mostra que já existem resultados importantes neste sentido (...) De entre todas as leis físicas, o Princípio da Menor Acção (...) é um dos princípios que, pela sua forma e compreensão, pode ser considerado como aquele que mais se aproximou deste objectivo (...)" (PLANCK, 1960: 69).

O Princípio da Menor Acção ou, mais apropriadamente, os princípios de acção estacionária ou princípios variacionais têm um lugar de destaque particular na descrição física da natureza. Estes princípios surgem da suposição que os fenómenos naturais podem ser matematicamente descritos por um processo de minimização (ou sendo mais preciso, de estacionaridade - máximo ou mínimo —) de uma determinada grandeza física. Todo o processo de cálculo é complexo, envolve algum detalhe analítico, e ele 
próprio, numa relação de cumplicidade mútua, esteve sempre associado à própria descoberta destes princípios.

A ideia que a natureza segue um princípio de esforço mínimo e que nada faz em vão, que poupa e economiza em todos os seus processos, é uma ideia bastante antiga que, desde há milénios, procurou ser transportada para os domínios de descrição das leis naturais. Foi o que fez Herão de Alexandria para explicar a igualdade entre os ângulos de reflexão e de incidência da luz. O Quadro I resume uma lista cronológica de algumas das principais contribuições em princípios variacionais ou de extremo lato sensu aplicados à Física.

De entre todos estes, talvez até pela importância que viria a assumir em toda a Física, aquele que levantou uma maior celeuma foi o Princípio da Menor Acção — inicialmente formulado por Maupertuis. Pode afirmar-se que, embora de nascimento difícil, os seus primeiros passos não suscitaram diatribes agressivas, foi maior a desconfiança, e talvez alguma indiferença, do que a violência. A polémica feroz ocorrida na Academia de Berlim, com foros de drama passional onde só faltaram, para a época, duelos de desafronta, opôs entre si alguns matemáticos e apaixonou alguns académicos, mas os ataques e as palavras duras passaram largamente ao lado da argumentação científica: a querela desenvolveu-se mais numa atmosfera de ataque pessoal (sob o signo da prioridade da descoberta), com contornos ideológicos, do que científica. Uma polémica — ainda hoje abundantemente referida — que acabou por ficar célebre, não pela discussão filosófico-científica, mas pela intervenção pública e contundente de um dos espíritos mais brilhante da Europa Iluminada do século XVIII - Voltaire. 
QUADRO I

\begin{tabular}{|c|c|}
\hline Autor & Princípio de extremo \\
\hline Herão de Alexandria & $\begin{array}{l}\text { A luz segue o percurso mais curto em meios homogéneos (re- } \\
\text { flexão) }\end{array}$ \\
\hline Ibn Haytham & A luz segue o caminho mais fácil (menos resistente) \\
\hline Fermat & Princípio do tempo mínimo (reflexão e refracção) \\
\hline Leibniz & A luz segue o caminho mais fácil (menos resistente) \\
\hline Maupertuis (1744) & $\begin{array}{l}\text { Princípio da Menor Acção: a luz segue o percurso que torna } \\
\text { menor essa quantidade }\end{array}$ \\
\hline $\begin{array}{l}\text { Euler (1744) } \\
\text { Lagrange }\end{array}$ & $\begin{array}{c}\text { Princípio da Menor Acção: aplicado a sistemas mecânicos cuja } \\
\text { energia é constante }\end{array}$ \\
\hline Lazare Carnot & $\begin{array}{c}\text { No seu Essai sur les machines en général deduz que a: "de tous } \\
\text { ces mouvements qui aura lieu réellement après l'action, est le } \\
\text { mouvement géométrique qui est tel, que la somme des pro- } \\
\text { duits de chacune des masses par le carré de la vitesse qu'elle } \\
\text { perdra est un minimum." }\end{array}$ \\
\hline Gauss (1929) & Princípio do Menor Constrangimento - aplicação à estática. \\
\hline Hamilton (1834) & Princípio de Hamilton: Aplicação à Óptica e à Mecânica \\
\hline Hertz & Princípio da Menor Curvatura \\
\hline Einstein \& Hilbert & Princípio Variacional aplicado à relatividade geral \\
\hline De Broglie (1923) & $\begin{array}{l}\text { Reunificação do Princípio de Fermat e do Princípio de Mauper- } \\
\text { tuis para as ondas de matéria }\end{array}$ \\
\hline Feynman (1948) & Princípio Variacional generalizado à mecânica quântica \\
\hline
\end{tabular}

Em torno da problemática da "menor acção", explicita ou implicitamente, intervieram todos os grandes espíritos da filosofia natural da época, isto é, dos séculos XVII e XVIII, nomeiam-se aqui os mais destacados: Pierre de Fermat (1601 - 1665); René Descartes (1596 - 1650); Christian Huyghens (1629 - 1695); Isaac Newton (1642 - 1727); Gottfried Leibniz (1646 - 1716); Jacob Bernoulli, (1654 - 1705); João (I) Bernoulli, (1667 - 1748); Pierre-Louis de Maupertuis (1698 - 1759); Samuel König (1712 - 1757); Leonard Euler (1707 - 1783); Daniel Bernoulli (1700 - 1782); VOLTAIRE (François-Marie Arouet) (1694 - 1778); Jean D’Alembert (1717 - 1783); Louis-Joseph Lagrange (1736 - 1813).

Os antecedentes, na génese moderna deste princípio, surgiram com Fermat ao demonstrar que, geometricamente, a lei da refracção da luz obedecia a um princípio de mínimo, isto é, o trajecto seguido pela luz é tal que o seu tempo é mínimo; a ideia de Fermat foi atacada pelos cartesianos que lhe lançaram 
o anátema de "princípio moral", retirando-lhe qualquer propósito de ser um "princípio físico". Mas este funcionamento de mínimo da natureza, simples hipótese matemática de Fermat, foi sendo, de tempos a tempos, lembrado: primeiro por Leibniz; depois por João (I) Bernoulli, já na viragem do século, ao utilizá-lo para resolver o problema da braquistócrona; posteriormente por Maupertuis e Euler que, ainda na Academia de Berlim, foram abordados por Lagrange e tomaram conhecimento das suas primeiras reflexões sobre as Recherches sur la méthode de maximis et minimis. O contexto de crescimento deste princípio, dentro da filosofia natural, foi marcado também pelo debate entre, por um lado, o dinamismo newtoniano e, por outro, a defesa dos princípios de conservação - um dos aspectos mais em evidência na célebre controvérsia entre Leibniz e Samuel Clarke (1675 - 1729).

Nas linhas que se seguem aborda-se exclusivamente a polémica que opôs Fermat a Descartes e aos Cartesianos em torno da proposta, feita pelo primeiro, de um princípio de tempo mínimo que explicaria de uma forma simples as leis da reflexão e refracção da luz. Em complemento apresentamos a tradução de três cartas, onde se expendem os pontos de vista de Fermat e dos discípulos de Descartes, que representam algumas das peças mais ilustrativas deste confronto. O texto aqui exposto corresponde à versão reduzida, e simplificada, de um dos primeiros capítulos de um livro que pretendemos publicar sobre a história d' O Princípio da Menor Acção e onde incluiremos a versão portuguesa de textos científicos e filosóficos mais significativos na trajectória deste Princípio. Porque é um dos trabalhos que neste momento desenvolvemos e pela oportunidade que nos é dada de participar neste livro, julgamos ser esta a forma mais adequada de exprimirmos ao Doutor António Amorim da Costa, além da estima e consideração que nos merece, a nossa cumplicidade pelo gosto e pela prática da investigação em História das Ciências.

\section{Fermat e Descartes}

As discussões e reflexões relativas à elaboração do Princípio da Menor Acção, ou de um princípio de mínimo que regulasse determinadas proprie- 
dades da natureza, iniciaram-se, no âmbito da Matemática, num debate que opôs Fermat a Descartes, e aos cartesianos, a propósito das leis da refracção óptica. Se estas leis foram o pretexto anunciador de uma polémica importante, outras razões, de carácter quer matemático quer filosófico, alimentaram o debate até ao ponto de se questionar o quadro geral de entendimento da natureza, isto é, a própria índole de um princípio deste tipo.

Foi o Padre Marin Mersenne (1588 - 1648), introdutor das ideias de Galileu em França e autor de uma das primeiras e mais relevantes teias de contacto entre os eruditos da época, que desencadeou todo o processo. Dentro dos seus múltiplos interesses de matemático e filósofo da natureza, correspondente assíduo de Descartes (1596 - 1650), Etienne Pascal (1588 - 1651), Blaise Pascal (1623 - 1662), Giles de Roberval (1602 - 1675), Pierre Gassendi (1592 - 1655) e muitos outros, o mais importante intermediário na circulação da informação escrita destas matérias fez chegar às mãos de Fermat as páginas da Dióptrica de Descartes, o primeiro ensaio da edição original do Discours de la Méthode et les Essais, escrita em francês e publicada em Leiden (Holanda) no ano de 1637; obra que só verá a sua versão latina no ano de 1644.

Fermat responde à solicitação de Mersenne, abrindo assim a primeira peça desta futura polémica, numa carta datada de abril ou maio de 1637, com a frase

"Pedis-me o meu juízo sobre o tratado de Dióptrica do Senhor Descartes. É verdade que o pouco tempo que o senhor Beaugrand me deu para o percorrer, parece dispensar-me da obrigação de vos satisfazer plenamente e com todos os pormenores; como o assunto é em si mesmo muito subtil e muito espinhoso, não ouso esperar que pensamentos informes, e não ainda bem digeridos, vos possam dar uma grande satisfação". (in DESCARTES, 1987(I): 355)

Para em seguida desenvolver alguns argumentos contra a concepção cartesiana, questionando as analogias ou "modelos" usados na Dióptrica. Um exemplo, Descartes usa a imagem de uma cuba de vinho, onde as uvas já estão em parte esmagadas, no sentido de explicar a transmissão do fenómeno luminoso: 
"essa matéria subtil sendo comparada com o vinho dessa cuba, e as partes menos fluidas ou mais granulosas, tal como o ar ou os outros corpos transparentes, com os cachos de uva que estão no seu interior" (in DESCARTES, 1982 (VI): 87)

É no seguimento desta "comparação" que Descartes chamou a atenção para a diferença entre "o movimento e a acção ou inclinação para se mover" (DESCARTES, 1982 (VI): 88). Isto é, dentro da cuba, caso se abrisse um orifício na sua parte lateral inferior, o vinho teria tendência a seguir um determinado movimento (percurso definido pelo segmento de recta que une o ponto onde se encontra o vinho e o ponto de saída), embora possa fluir de outro modo porque ainda existiriam uvas a barrar-lhe o caminho. Descartes concluiu que a luz não devia ser entendida como movimento, enquanto acção de corpos luminosos, mas sim como as linhas através das quais essa acção terá tendência a mover-se. Estava assim concebido o percurso rectilíneo dos raios luminosos (embora, tal como o vinho, a sua marcha pudesse ser muito sinuosa), advindo desde logo a possibilidade de os tratar como entidade geométrica (FITAS, 2001). Contudo, Fermat nesta primeira carta, e ainda a polémica não tinha saído para o adro, já deixava um primeiro aviso - geometria é uma coisa, outra é a física:

"Mas a Geometria não se associa de modo nenhum ao aprofundamento em maior grau das matérias da Física." (in DESCARTES, 1987( I): 358).

O raciocínio de Descartes para a explicação da reflexão e refracção assentava em associar essa "inclinação para se mover" ao movimento de um projéctil que se podia decompor em duas componentes, uma normal á superfície de separação dos dois meios e a outra paralela a essa mesma superfície. Assim na reflexão, porque não há penetração no segundo meio, quando um projéctil choca com uma parede, altera-se a primeira componente e mantém-se constante a segunda, o que levaria a concluir sobre a igualdade dos ângulos de incidência e reflexão. No caso da refracção, mantinha-se o princípio de não alterar a componente (paralela) do movimento, alterando-se a componente normal na mediada em que a velocidade do movimento diferia 
nos dois meios, assumindo Descartes a hipótese que essa velocidade era maior num meio mais denso, isto é, maior na água do que no ar...

Pierre de Fermat, com uma formação em direito, jurista e magistrado por profissão, interessava-se por matemática ${ }^{1}$ e, entre outros temas, estudou métodos algébricos para resolver problemas geométricos e escreveu uma obra que não chegou a publicar em vida, Método para determinar os máximos e minimos ${ }^{2}$, onde desenvolve um método de determinação de máximos e mínimos, determinando analiticamente a tangente a uma curva. Longe dos círculos de Paris, habitava na cidade de Toulouse, em 1636 iniciou a sua correspondência com Roberval e Marin Mersenne. No grupo de correspondentes deste último, mesmo em cima da publicação do Discurso do Método, já era instado a pronunciar-se sobre a Dióptrica, exprimindo cautelosamente as suas dúvidas sobre a teoria explicativa de Descartes:

“(...) eu duvido primeiramente, e com razão, segundo me parece, se a inclinação para o movimento deve seguir as mesmas leis do próprio movimento, visto que há uma tão grande diferença entre um e outro como a que vai da potência ao acto." (in DESCARTES, 1987 (I): 357)

Eis um raciocínio com premissas aristotélicas que não deve ter agradado a Descartes. Neste texto, Fermat destaca em particular três pontos de dúvida ou desacordo: o tratamento igual entre movimento e inclinação para o movimento, o carácter da demonstração geométrica utilizada por Descartes para a reflexão e, ainda de um modo pouco explícito, a forma como variava a velocidade do projéctil com as propriedades do meio. De qualquer modo porque a carta não é muito desenvolvida termina com a mensagem

"Tudo o que acabo de vos dizer não impede que não tenha em grande estima o espírito e a criação do autor, mas é necessário em conjunto procurar a verdade, o que eu creio nos estar ainda vedado sobre este assunto" (in DESCARTES, 1987 (I): 360).

Mersenne, secretário geral não empossado da República das Letras, dará a conhecer a opinião de Fermat a Descartes, talvez com algum atraso pois 
este só lhe responde a 5 de Outubro numa carta onde Fermat jamais é nomeado e que começa assim

"Comunicais-me que um dos vossos amigos viu a Dióptrica, tendo algumas objecções a fazer-lhe" (DESCARTES, 1987 (I): 450).

Descartes, citando vários passos da carta de Fermat, limita-se a reafirmar os seus argumentos, não acrescentando nada de novo. A carta recebida por Mersenne será enviada a Fermat e este elabora a sua primeira resposta, onde a crítica ao método cartesiano de determinação da lei da refracção é a substância de todo o texto. É uma carta, datada provavelmente de Novembro de 1637, bastante mais extensa, onde é posto em causa que a direcção do raio, ao passar de um meio para outro (mais denso), seja unicamente afectada, na sua componente normal, pela superfície de separação dos dois meios. Este facto obrigaria o raio a aproximar-se da normal, exigindo-se assim, pela analogia com o movimento do projéctil, que aquele adquirisse maior velocidade. Embora esta questão do aumento de velocidade no meio mais denso, naquele que oferece maior resistência ao movimento, vá ser, mais tarde, o ponto central da discordância, em matéria de Física, entre Fermat e os cartesianos, nesta carta a objecção condensa-se em torno do comportamento diferente das duas componentes do movimento.

Em Janeiro de 1638 Descartes responde a Fermat, dirigindo a sua carta a Mersenne, mas afasta-se do tema que até aí os ocupara (a demonstração da lei da refracção), para se pronunciar sobre o trabalho Método para determinar os máximos e mínimos que, entretanto, Fermat lhe terá feito chegar por intermédio de amigos comuns. É de supor que no intervalo entre estas duas últimas cartas, Novembro a Janeiro, Fermat tenha tomado conhecimento com o terceiro ensaio que se seguia ao Discurso do Método, A Geometria, e, ele próprio um geómetra que desenvolvera alguns métodos algébricos para tratar problemas geométricos, sentiu-se na obrigação de dar a conhecer, ao criador da Geometria Analítica, os seus trabalhos. Descartes começa por escrever: 
"Mas porque eu reconheço que aquele mesmo que se encarregou de refutar a minha dióptrica e que haveis comunicado para que ma [Método para determinar os máximos e mínimos] enviasse depois de ter lido a minha geometria (...) depois também, por causa do que aprendi nas vossas cartas de que ele tem a reputação de ser bastante sábio em geometria, sinto-me obrigado a responder-lhe" (DESCARTES, 1987 (I): 486).

A carta é curta e desenvolve-se em torno da geometria. A resposta aos argumentos de Fermat sobre a refracção será dada numa outra carta que Descartes envia a Claude Mydorge $\left(1585\right.$ - 1647) ${ }^{3}$, e a troca de pontos de vista morre por aqui ou, tanto quanto se saiba, em vida de Descartes os dois contendores não esgrimirão mais argumentos em torno da Dióptrica. Contudo, porque a obra de Fermat, que fora mencionada, tinha a ver com métodos analíticos aplicados à Geometria, existirá da parte de Descartes, uma certa animosidade contra a proposta matemática de Fermat, escrevendo nesta carta a Mydorge

"De maximis \& minimis, que me enviou, para mostrar que eu tinha esquecido essa matéria na minha Geometria, e também que tinha uma maneira de encontrar as tangentes das linhas curvas, melhor que a que eu tinha dado" (DESCARTES, 1987 (II): 16).

E, segundo alguns autores (CALINGER, 1999: 517), essa animosidade levou-o a empenhar-se, chegando mesmo a consegui-lo, que a obra de Fermat não fosse publicada pelo editor Elsevier.

A polémica, em torno da Óptica, reacender-se-á com argumentos de muito maior peso filosófico entre Fermat e os seguidores de Descartes. Sintetiza-se a relação completa das peças desta polémica no Quadro II. A discussão com Descartes resume-se a uma discordância nas demonstrações sobre as leis da reflexão e da refracção, Fermat não explicitara ainda qualquer outro princípio que permitisse fundamentar e demonstrar essas mesmas leis. A discussão à volta do princípio do tempo mínimo só surgiu na correspondência com os discípulos de René Descartes. 
Quadro II

\begin{tabular}{|c|c|c|c|c|}
\hline $\mathrm{N}^{\mathrm{o}}$ & Carta & Data & Referência & $\begin{array}{c}\text { Pág. } \\
\text { inicial }\end{array}$ \\
\hline LXXII & Fermat a Mersenne & Maio de 1637 & DESCARTES, 1987 (I) & 354 \\
\hline $\mathrm{XCI}$ & Descartes a Mersenne & $\begin{array}{c}5 \text { de outubro } \\
\text { de } 1637\end{array}$ & DESCARTES, 1987 (I) & 450 \\
\hline XCVI & Fermat a Mersenne & $\begin{array}{c}\text { Novembro de } \\
1637\end{array}$ & DESCARTES, 1987(I) & 463 \\
\hline XCVIII & Descartes a Mersenne & $\begin{array}{l}\text { Janeiro de } \\
1638\end{array}$ & DESCARTES, 1987 (I) & 481 \\
\hline XCIX & Descartes a Mersenne & $\begin{array}{c}\text { Janeiro de } \\
1638\end{array}$ & DESCARTES, 1987 (I) & 486 \\
\hline $\mathrm{CI}$ & Descartes a Mersenne & $\begin{array}{c}25 \text { de janeiro } \\
\text { de } 1638\end{array}$ & DESCARTES, 1987 (I) & 499 \\
\hline CXI & $\begin{array}{c}\text { Descartes a Mydorge } \\
\text { para Fermat }\end{array}$ & $\begin{array}{l}1 \text { de março } \\
\text { de } 1638\end{array}$ & $\begin{array}{c}\text { DESCARTES, } 1987 \\
\text { (II) }\end{array}$ & 15 \\
\hline LXXXVI & Fermat a La Chambre & $\begin{array}{l}\text { Agosto de } \\
1657\end{array}$ & FERMAT, 1891 (II) & 354 \\
\hline $\mathrm{XC}$ & Fermat a Clerselier & $\begin{array}{l}3 \text { de março } \\
\text { de } 1658\end{array}$ & FERMAT, 1891 (II) & 365 \\
\hline $\mathrm{XC}$ bis & Fermat a Clerselier & $\begin{array}{c}10 \text { de março } \\
\text { de } 1658 \\
\end{array}$ & FERMAT, 1891 (II) & 367 \\
\hline XCIII & Clerselier a Fermat & $\begin{array}{l}15 \text { de maio } \\
\text { de } 1658\end{array}$ & FERMAT, 1891 (II) & 382 \\
\hline XCIV & $\begin{array}{c}\text { Rohault a Clerselier } \\
\text { para Fermat }\end{array}$ & $\begin{array}{l}15 \text { de maio } \\
\text { de } 1658\end{array}$ & FERMAT, 1891 (II) & 391 \\
\hline $\mathrm{XCV}$ & Fermat a Clerselier & $\begin{array}{l}2 \text { de junho } \\
\text { de } 1658\end{array}$ & FERMAT, 1891 (II) & 397 \\
\hline XCVII & Clerselier a Fermat & $\begin{array}{c}16 \text { de junho } \\
\text { de } 1658\end{array}$ & FERMAT, 1891 (II) & 408 \\
\hline XCIX & Clerselier a Fermat & $\begin{array}{c}21 \text { de agosto } \\
\text { de } 1658\end{array}$ & FERMAT, 1891 (II) & 414 \\
\hline CXII & Fermat a La Chambre & $\begin{array}{c}1 \text { de janeiro } \\
\text { de } 1662\end{array}$ & FERMAT, 1891 (II) & 457 \\
\hline CXIII & Clerselier a Fermat & $\begin{array}{c}6 \text { de maio de } \\
1662 \\
\end{array}$ & FERMAT, 1891 (II) & 464 \\
\hline CXIV & Clerselier a Fermat & $\begin{array}{c}13 \text { de maio } \\
\text { de } 1662\end{array}$ & FERMAT, 1891 (II) & 472 \\
\hline CXV & Fermat a Clerselier & $\begin{array}{l}21 \text { de maio } \\
\text { de } 1662\end{array}$ & FERMAT, 1891 (II) & 482 \\
\hline
\end{tabular}




\section{Fermat e os cartesianos}

Em 1657, o médico e conselheiro do rei Luís XIV, De La Chambre (1596 1669), reconhecido cartesiano, publicou em Paris uma obra, La Lumière, e enviou a Fermat um exemplar no sentido de recolher a sua opinião (FERMAT, 1891 (II): 354). Fermat escreve-lhe e, no segundo parágrafo desta missiva, inscreve um princípio de mínimo, assumindo que a "natureza age sempre pela via mais curtas", sendo essa a forma de demonstrar agilmente as leis da reflexão:

"Reconheço em primeiro lugar como vós a verdade deste princípio, que a natureza age sempre pelas vias mais curtas. Daí deduzis muito bem a igualdade dos ângulos de reflexão e de incidência, e a objecção dos que dizem que as duas linhas que conduzem a vista ou a luz no espelho côncavo são muitas vezes as mais longas, não merece a menor consideração, se suponhais apenas, como outro princípio inquestionável, que tudo o que se apoia ou resiste a uma linha curva, qualquer que seja a natureza desta, é suposto apoiar-se ou resistir a uma linha recta que toque a curva no ponto onde elas se encontram: o que pode ser provado por um argumento físico com a ajuda de um outro geométrico.

O princípio da Física é aquele que sustenta que a natureza faz os seus movimentos através das vias mais simples." (FERMAT, 1891 (II): 354)

Colocada a questão neste pé, Fermat apressa-se a propor a utilização do mesmo princípio para encontrar a lei da refracção:

"Mas, já que serve para a reflexão, poderíamos dele tirar proveito para a refracção? Parece-me que a coisa é fácil e que um pouco de geometria nos pode resolver o assunto" (FERMAT, 1891 (II): 355).

Para no parágrafo imediato relembrar a troca de argumentos já havida entre si e Descartes:

"Não me vou alongar na refutação da demonstração do Sr. Descartes. Já lha contestei antes (...) mas ainda não estou satisfeito (..) Mas é pre- 
ciso ir mais longe e encontrar a razão da refracção no nosso princípio comum, de que a natureza age sempre pelas vias mais curtas e mais fáceis. "(FERMAT, 1891 (II): 356)

E, ao passar ao estudo da refracção, Fermat, partindo do princípio que o percurso da luz entre dois pontos C e A (fig.1), situados em dois meios diferentes separados pela linha BD tal que a resistência de um meio seja o dobro da do outro, enuncia o problema do seguinte modo:

“(...) é preciso procurar o ponto $\mathrm{B}$ no qual o raio, que vai de $\mathrm{C}$ a $\mathrm{A}$ ou de A a C, é cortado ou quebrado.

Se supomos que a questão já está resolvida, e que a natureza age sempre pelas vias mais curtas e mais fáceis, a resistência por CB, junta à resistência por BA, conterá a soma das duas resistências, e esta soma, para satisfazer ao princípio, deve ser a menor de todas as que se podem encontrar em qualquer outro ponto da linha DB. Ora estas duas resistências juntas são neste caso, como provámos, representadas: ou pela linha CB junta a metade da BA, ou pela mesma linha CB junta ao dobro da BA.

A questão reduz-se portanto a este problema de Geometria:

Dados os dois pontos $\mathrm{C}$ e $\mathrm{A}$ e a recta $\mathrm{DB}$, encontrar um ponto na recta $\mathrm{DB}$ no qual se você fizer convergir as rectas $\mathrm{CB} e \mathrm{BA}$, a soma de $\mathrm{CB} e$ da metade de BA corresponde à menor de todas as somas possiveis de obter pela mesma forma, ou então que a soma de $\mathrm{CB}$ e do dobro de $\mathrm{BA}$; corresponde à menor de todas as somas que podem ser obtidas de forma semelhante;

e o ponto B que será encontrado pela construção deste problema será o ponto em que se fará a refracção." (FERMAT, 1891 (II): 357) 


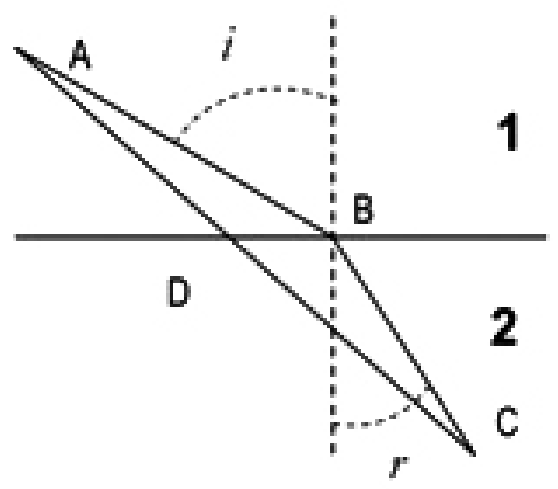

Fig.1

A carta termina com mais dois ou três parágrafos, onde nada de essencial é acrescentado. De La Chambre não responderá directamente a Fermat e o debate prossegue com outros interlocutores. Fermat recebeu depois uma carta de Claude Clerselier (1614-1684), o primeiro editor da correspondência de Descartes, em que este lhe enviou as cópias das cartas que Descartes lhe mandara, solicitando-lhe que refizesse as respostas dadas. Respondeu Fermat:

"as duas cópias dos dois escritos do sr. Descartes sobre o assunto da nossa antiga disputa (...) Gostaria muito, senhor, de vos satisfazer pontualmente no que diz respeito ao vosso pedido para que eu refaça as minhas respostas de então e que se extraviaram (...)" (FERMAT, 1891 (II): 365)

Desapareceram as cartas e é necessário reescrevê-las. É o que propõe Fermat na carta seguinte, datada de 10 de março de 1658, refazendo todo o raciocínio em que punha em causa a demonstração apresentada por Descartes sobre o percurso do raio luminoso no fenómeno da refracção óptica. Clerselier e Rohault (1620-1672) vão-lhe responder separadamente, tomando a defesa de Descartes. Também não há novos argumentos nas respostas de Fermat de 16 de Junho e de 21 de Agosto.

Em 1 de Janeiro de 1662, Fermat retoma a correspondência com De La Chambre, assumindo a polémica um cariz diferente. Já não se trata de estar, ou não, de acordo com as demonstrações cartesianas, mas o que vai estar 
em jogo é o princípio usado por Fermat para, de um modo alternativo, demonstrar a lei da refracção. É em torno da natureza deste princípio e das suas consequências que se prenderá a atenção dos cartesianos. Nesta carta ${ }^{4}$, logo no segundo parágrafo, escreve-se:

"o Sr. Descartes nunca demonstrou o seu princípio; porque, além das comparações não servirem em nada na fundamentação das demonstrações, o emprego que faz delas é um contra-senso e supõe mesmo que a passagem da luz é mais fácil pelos corpos densos do que pelos rarefeitos, o que aparentemente é falso. Não lhe vou repetir nada sobre a falta de demonstração em si mesma, se bem que a comparação de que ele se serve seja boa e admissível nesta matéria, pelo facto de já ter tratado tudo isso nas minhas cartas para o Sr. Descartes enquanto estava vivo, ou nas que escrevi ao Sr. Clerselier depois da sua morte" (FERMAT, 1891 (II): 457).

O argumento de Descartes era o que expusera na sua Dióptrica, e que Fermat considerava "aparentemente falso", uma aparência que dizia respeito a um acordo com o "senso comum", e se passa a transcrever:

“(..) vós deixareis contudo de achar a coisa estranha, se vos lembrardes da natureza que atribuí à luz, ao dizer que ela não era outra coisa senão um certo movimento ou uma acção recebida numa matéria tão subtil que preenche os poros dos outros corpos; e que considerais que, como uma bala perde em maior grau a sua agitação, ao chocar contra um corpo mole do que contra um que é duro, e que rola menos facilmente sobre um tapete do que sobre uma mesa nua, assim a acção desta matéria subtil pode muito mais ser impedida pelas parte do ar que, sendo moles e mal aglutinadas, não lhe oferecem muita resistência, do que pelas da água que lhe oferecem resistência em maior grau, e ainda mais pelas da água do que pelas do vidro ou do cristal. De tal forma que, quanto mais duras e mais firmes são as pequenas partes de um corpo transparente, mais facilmente deixam passar a luz: porque essa luz não tem que empurrar algumas para fora das suas posições, tal como uma bala deve afastar as partículas de água para conseguir passar através delas." (DESCARTES, 1982 (VI), 103) 
Para Fermat estes argumentos não tinham sentido e por isso retoma a argumentação já exposta a De La Chambre na carta de Agosto de 1657 e que, segundo parece, ainda não era do conhecimento do círculo dos discípulos de Descartes; escreve Fermat:

"Para sair desta confusão e tentar encontrar a verdadeira razão da refracção, sugeri-a-vos na minha carta que, se quiséssemos empregar nesta investigação o princípio tão comum e já tão aceite, que a natureza age sempre pelas vias mais curtas, poderíamos encontrar facilmente nele a nossa explicação." (in FERMAT, 1891 (II): 458)

E este caminho "mais curto" corresponde a uma determinação de mínimo feita por intermédio do método que o geómetra tinha desenvolvido e que anteriormente já fora referido.

"Cheguei aí sem grande esforço, mas foi preciso levar a investigação mais longe e, porque, para satisfazer com o meu princípio, não basta ter encontrado um ponto $\mathrm{F}$, por onde o movimento se realiza mais rapidamente, mais facilmente e em menos tempo do que pela recta (...), mas [que] é preciso ainda encontrar o ponto através do qual se faz o percurso em menos tempo do que através de qualquer outro que seja, tomado dos dois lados, foi-me necessário nesta ocasião recorrer ao meu método de maximis et minimis, que resolve este tipo de questões com bastante sucesso". (in FERMAT, 1891 (II): 460)

Esta carta é acompanhada de um texto separado, Analysis ad Refractiones - e/ ou de um outro texto intitulado Synthesis ad Refractiones ${ }^{5}$ - onde Fermat pormenorizava matematicamente a sua dedução. A conclusão, extraída por Fermat para a refracção, é a já conhecida lei dos senos, mas com um resultado físico inverso do encontrado por Descartes: a velocidade de propagação da luz seria menor no meio mais denso, o que estaria de acordo com aquilo que intuira e de que já chamara a atenção ao autor da Dióptrica. Por outras palavras, a razão entre o seno do ângulo de incidência (meio 1 ou rarefeito) e o seno do ângulo de refracção (meio 2 ou denso) seria 
igual à razão entre as velocidades dos dois meios (ou à razão inversa das resistências dos meios à propagação da luz), este era o resultado de Fermat, para Descartes era exactamente o inverso. E, ao terminar a carta, Fermat apostrofava todos os "amigos do Sr. Descartes" sobre a sua incapacidade em verificar esta "verdade natural", o meio mais denso ofereceria maior resistência, logo a velocidade seria menor:

"Repeti diversas vezes as minhas operações algébricas e o resultado foi sempre o mesmo, apesar de a minha demonstração supor que a passagem da luz pelos corpos densos é mais difícil do que pelos rarefeitos, o que creio ser verdadeiro e indiscutível, e que todavia o Sr. Descartes supõe o contrário." (in FERMAT, 1891 (II): 462).

Quase a terminar e antes de convidar todos os cartesianos a pensarem na demonstração que apresentara, declara:

"Acrescento mesmo, em favor do seu amigo, que parece que esta grande verdade natural não ousou resistir a este grande génio, e que ela se lhe rendeu à descoberta sem se deixar forçar pela demonstração, a exemplo dessas praças que, ainda que bem guarnecidas e de difícil conquista, não deixam, pela simples reputação dos que as atacam, de render-se sem esperar o disparo dos canhões" (in FERMAT, 1891 (II): 462).

Foi com esta carta que a polémica em torno do princípio de Fermat estalou verdadeiramente. De La Chambre comunicou à Assembleia dos seguidores de Descartes a proposta de Fermat sobre a demonstração das leis da refracção e, a partir daí, a discussão deixa de se situar sobre um fenómeno natural, mas passa desenrolar-se sobre as razões do comportamento da natureza. Clerselier, a 6 de Maio de 1662, vai responder-lhe em nome da "Assembleia dos cartesianos", pronunciando-se sobre o "princípio" utilizado por Fermat:

"O princípio que tomais como fundamento da vossa demonstração, ou seja que a natureza age sempre pelas vias mais curtas e mais simples, 
é apenas um princípio moral e nada físico, que não é e que não pode ser a causa de qualquer efeito da natureza.

Não o é, porque não é este princípio que a faz agir, mas sim a força secreta e a propriedade que há em cada coisa, que nunca é determinada para a este ou aquele efeito por esse princípio, mas pela força que existe em todas as causas que concorrem em conjunto para uma mesma acção, e pela disposição que se encontra realmente em todos os corpos sobre os quais esta força age." (in FERMAT, 1891 (II): 465)

A natureza não sabe como agir, portanto não pode tomar essa decisão de tempo mínimo, fisicamente a natureza só pode agir através da acção do movimento sobre os corpos — forma simplificada do mecanismo cartesiano. Os princípios para lá dessa actuação, ou seja, a razão pela qual isso se passa - é assim que pode ser entendido esse princípio de mínimo - está para lá da física, diz respeito ao domínio da metafísica. Clerselier estende a sua argumentação ao facto de tudo o que acontece ser independente do tempo

"Como não é o tempo que se move, também não pode ser ele que determina o movimento, não há nenhuma aparência que possa fazer crer que o tempo mais ou menos breve possa obrigar este corpo a mudar de determinação, visto que não age e não tem nenhum poder sobre ele." (in FERMAT, 1891 (II): 466)

Sublinhando a impossibilidade de o raio partindo do ponto $\mathrm{M}$, ao chegar ao ponto sobre a superfície que delimita os dois meios, ponto N,

"se lembrou que partiu do ponto $\mathrm{M}$ com ordem para procurar, ao encontrar este outro meio, o caminho que pudesse percorrer em menos tempo para a partir daí chegar a H: o que, em boa verdade, é imaginário e sem nenhum fundamento na Física." (in FERMAT, 1891 (II): 467)

Atitude que, no ponto de vista dos cartesianos, corresponde às causas finais aristotélicas ou ainda a um princípio que, apelando a uma permanente intervenção de uma super inteligência, regularia todos os actos da natureza. 
Explicava-se o comportamento da natureza à luz de qualquer coisa que lhe era estranha. E, para concluir, Clerselier acentua o aspecto elementar que sempre estivera em causa

"Afinal a diferença que encontro entre o Sr. Descartes e vós é que vós não provais nada, mas supondes por princípio que a luz passa mais facilmente pelos corpos rarefeitos do que pelos densos; enquanto que o Sr. Descartes prova, e não supõe simplesmente, como dizeis, que a luz passa mais facilmente pelos corpos densos do que pelos rarefeitos." (in FERMAT, 1891 (II): 470)

Chegado a este ponto Fermat pouco mais tem a dizer e a polémica termina com uma carta, datada de 21 de Maio de 1662, onde laconicamente afirma não pretender ser o "confidente secreto da natureza":

"Quanto à questão principal, parece-me que eu disse muitas vezes ao Sr. de la Chambre e a vós que não pretendo nem nunca pretendi ser confidente secreto da Natureza. Ela tem caminhos obscuros e ocultos em que nunca tentei penetrar; tinha-lhe apenas oferecido um pequeno recurso de geometria relativamente à refracção, se ela tivesse necessidade dele. Mas uma vez que vós, Exmo. Senhor, me garantis que ela pode resolver os seus assuntos sem essa ajuda e se satisfaz com a maneira de agir que o Sr. Descartes lhe prescreveu, dispenso-vos de boa vontade a minha pretensa conquista de física, e basta-me que me deixais na posse do meu problema de geometria puro e in abstracto, por meio do qual se pode encontrar a trajectória de um objecto móvel que passa por dois meios diferentes e que procura realizar o seu movimento no menor tempo possível." (in FERMAT, 1891 (II): 483).

Se a física cartesiana não se compadece com os seus - de Fermat métodos matemáticos, paciência, ele mantém o seu princípio. É certo que é um princípio de natureza teleológica, determinado por cálculo matemático, embora não sustentado pela observação empírica... 


\section{Referências bibliográficas}

Calinger, Ronald. 1999. A contextual history of mathematics to Euler. New Jersey: Prentice-Hall.

Descartes. 1987. CEUVRES DE DESCARTES (publiées par Charles Adam \& Paul Tannery). 13 volumes. Paris: Librairie Philosophique J. Vrin.

Fermat. 1891. CEUVRES DE FERMAT (publiées par Paul Tannery \& Charles Henry). 5 volumes. Paris: Gauthiers-Villars fils.

Fitas, A.J.. 2001. A ÓPTICA E O ARCO ÍRIS, breves reflexões sobre os "modelos" e as "experiências" em Descartes. In Seminário sobre O Cartesianismo. Évora: Universidade de Évora- CEHFC, 223-240.

Planck, Max. 1960. A survey of physical theory. New York: Dover Pub. Inc.

\section{Troca de cartas entre Fermat e os cartesianos}

Seguidamente apresentam-se as traduções das cartas que no Quadro-II são referenciadas pelo números CXII (FERMAT, 1891 (II): 457-463), CXIII (FERMAT, 1891 (II): 464-472) e CXV (FERMAT, 1891 (II): 482-484). Nas cartas traduzidas as figuras mantêm a numeração original e as notas de rodapé, embora sejam as originais, têm uma numeração diferente; não se apresentam quaisquer notas referentes à tradução e à interpretação dos textos originais, embora, em publicação posterior, isso venha a ser feito. As traduções foram realizadas pelo Prof. Joaquim Quitério, a quem agradeço penhoradamente a sua sempre pronta e desinteressada colaboração, e posteriormente revistas pelo autor deste artigo.

\subsection{Carta ${ }^{\circ}$ CXII (de Fermat para C. de La Chambre)}

Datada de Domingo, 1 de Janeiro de 1662

Exmo. Senhor,

1. É justo que vos obedeça e que ponha finalmente termo, por vosso intermédio, à velha querela que existe há tanto tempo entre o Sr. Descartes 
e eu sobre a questão da refracção, e talvez fique muito feliz por propor-vos uma paz que considerareis vantajosa para todas as partes.

Disse-vos há tempos, na minha primeira carta ${ }^{6}$, que o Sr. Descartes nunca demonstrou o seu princípio, porque, além das comparações não servirem para nada na fundamentação das demonstrações, o emprego que faz dela é um contra-senso e supõe mesmo que a passagem da luz é mais fácil nos corpos densos do que nos rarefeitos, o que aparentemente é falso. Não vos repito nada sobre a falta de demonstração em si mesma, se bem que a comparação de que ele se serve seja boa e admissível nesta matéria, pelo facto de ter tratado tudo isso nas minhas cartas para o Sr. Descartes quando ainda estava vivo, ou nas que escrevi ao Sr. Clerselier depois da sua morte ${ }^{7}$

2. Acrescento apenas que tendo visto o mesmo princípio do Sr. Descartes em vários autores que escreveram depois dele, as suas demonstrações também não me pareceram aceitáveis de modo nenhum e não merecem esse nome: Hérigone ${ }^{8}$ serve-se, para o demonstrar, dos equiponderantes e da relação dos pesos nos planos inclinados; o padre Maignan 9 quer chegar lá de uma outra maneira. Mas é fácil ver que nem um nem outro o demonstram, e que depois de ter lido e examinado com atenção as suas demonstrações, continuamos com tantas dúvidas sobre a verdade dos princípios como depois de ter lido o Sr. Descartes.

Para sair desta confusão e tentar encontrar a verdadeira razão da refracção, sugeri-vos na minha carta que, se quiséssemos empregar nesta investigação o princípio tão comum e já tão aceite, que a natureza age sempre pelas vias mais curtas, poderíamos encontrar facilmente nele a nossa explicação. Mas como vós começastes por duvidar que a natureza, ao conduzir a luz pelos dois lados dum triângulo, possa agir por uma via tão curta com se a conduzisse pela base ou pela linha subtensa, vou fazer-vos ver o contrário daquilo que pensais ou, melhor, daquilo que duvidais, através de um exemplo fácil.

3. Seja, na figura à parte (fig. 100), o círculo ACBG, cujo diâmetro seja AOB, o centro O e um outro diâmetro GOC. Dos pontos G e C tirem-se as perpendiculares ao primeiro diâmetro, GH, CD. Suponhamos que o primeiro diâmetro AOB separa dois meios diferentes, dos quais um que é o de debaixo, AGB, é mais denso e o de cima, ACB, é o mais rarefeito, de tal maneira, por exemplo, que a passagem pelo mais rarefeito seja mais fácil do que pelo mais denso na razão do dobro. 
Segue-se desta suposição que o tempo que emprega o móvel, ou a luz, no movimento de $\mathrm{C}$ a O é menor que o que os conduz de O a $\mathrm{G}$, e que o tempo do movimento de $\mathrm{C}$ a $\mathrm{O}$, que é feito no meio mais rarefeito, é apenas metade do tempo do movimento de O a G. E, por consequência, a medida do movimento total pelas duas rectas CO e OG pode ser representado pela soma da metade de CO e da total OG; da mesma forma, se tomardes outro ponto, como F, o tempo do movimento pelas duas rectas CF e FG pode ser representado pela soma de metade de CF e da total FG.

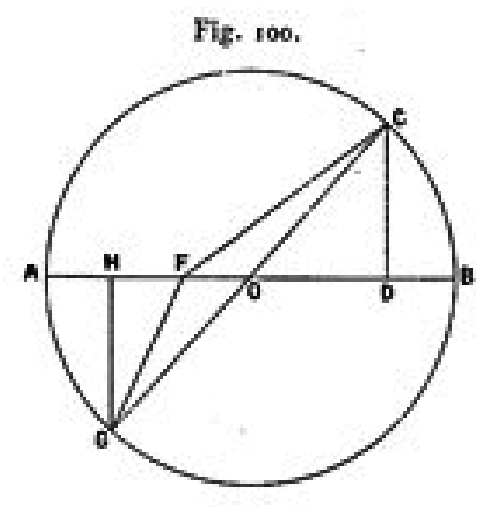

Suponhamos agora que o raio CO seja 10, e por consequência o diâmetro total COG seja 20, que a recta $\mathrm{HO}$ seja 8 , a recta OD também 8 , e que por fim a recta OF seja apenas 1 . Digo que neste caso o movimento que se faz pela recta COG se fará num tempo mais longo do que o que se faz pelos dois lados do triângulo, CF e FG.

Porque se provarmos que a metade de CO, junta à total de OG, contém mais que a metade de CF somada com a total de FG, a conclusão será evidente, uma vez que as duas somas são justamente a medida do tempo desses dois movimentos. Ora a soma da metade de CO e da total de OG perfaz justamente 15, e é evidente pela construção que a recta CF é igual à raiz quadrada de 117 e que a recta FG é igual à raiz quadrada de 85 . Mas a metade da primeira, somada à segunda, perfaz menos do que 59/4, e 59/4 são ainda menores que 15. Portanto a soma da metade de CF e da total FG é menor que a soma da metade de CO e da total OG, e portanto 
o movimento pelas duas rectas CF e FG faz-se antes e em menos tempo do que pela base ou pela linha subtensa COG.

4. Cheguei aí sem grande esforço, mas foi preciso levar a investigação mais longe e, porque, para satisfazer com o meu princípio, não basta ter encontrado um ponto $\mathrm{F}$, por onde o movimento se realiza mais rapidamente, mais facilmente e em menos tempo do que pela recta COG, mas [que] é preciso ainda encontrar o ponto através do qual se faz o percurso em menos tempo do que qualquer outro que seja, tomado dos dois lados, foi-me necessário nesta ocasião recorrer ao meu método de maximis et minimis que resolve este tipo de questões com bastante sucesso.

Desde que decidi empreender esta análise, tive de ultrapassar dois obstáculos: o primeiro, que, embora estivesse seguro da verdade do meu princípio, que é o de não haver nada de tão provável nem de tão aparente como esta suposição, de que a natureza age sempre pelos meios mais fáceis, ou seja pelas linhas mais curtas, quando elas não levam mais tempo, ou, em qualquer o caso, pelo tempo mais curto, para abreviar o seu trabalho e chegar mais rapidamente ao fim da sua operação (o que o cálculo precedente confirma, tanto mais quanto parece que a luz tem mais dificuldade em atravessar os meios densos que os rarefeitos, pois vedes que a refracção tende para a perpendicular no meu exemplo, tal como a experiência o confirma, o que no entanto é contrário à suposição do Sr. Descartes). Todavia fui avisado por todas as vias, e principalmente pelo Sr. Petit, por quem tenha uma estima infinita, que as experiências concordam exactamente com a proporção que o Sr. Descartes deu às refracções, e que, apesar de a sua demonstração ter falhas, é de recear que seja inútil a minha tentativa de introduzir uma proporção diferente da sua, e que as experiências que serão feitas depois de eu publicar a minha invenção, poderão destruí-la na hora.

O segundo obstáculo que se opôs à minha investigação foi a extensão e a dificuldade do cálculo, que, na resolução do problema de que vos falei na minha carta e que testemunhastes não serem dos mais fáceis, apresenta desde logo quatro linhas pelas suas raízes quadradas e implica por consequência em assimetrias que resultam numa enorme extensão.

Desembaracei-me do primeiro obstáculo pelo conhecimento que tenho de que há infinitas proporções, diferentes da verdadeira, que se aproximam 
dela tão insensivelmente que podem enganar os mais hábeis e exactos observadores. Assim, ficando apenas com o segundo obstáculo a vencer, tomava muitas vezes a resolução de empregar a bem amada ${ }^{10}$ Geometria (é assim que Plutarco lhe chama) para vos satisfazer e para me satisfazer a mim próprio. Mas a preocupação com a possibilidade de encontrar, após uma longa e penosa operação, alguma proporção irregular e bizarra, e a propensão natural que eu tenho para a preguiça, deixaram a coisa neste estado, até à última recriminação da vossa parte que o Sr. Presidente [de] Miremont acaba de me fazer, que tomo como uma lei mais forte que a minha preocupação e a minha preguiça: assim resolvi obedecer-vos sem mais demora.

5. Procedi portanto sem tardar, por dever de obediência, como dizem os monges, à execução das vossas ordens, e fiz a análise formal completa, em que o veemente desejo que tinha de vos satisfazer me inspirou um caminho que abreviou para metade o meu trabalho e que reduziu as quatro assimetrias com que eu contava da primeira vez a apenas duas, o que me aliviou extraordinariamente. Mas o prémio do meu trabalho foi o mais extraordinário, o mais imprevisto e o mais feliz de sempre. Porque, depois de ter corrido por todas as equações, multiplicações, antíteses e outras operações do meu método, e ter por fim concluído a resolução do problema que vereis no papel em separado ${ }^{11}$, descobri que o meu princípio dava justa e precisamente a mesma proporção das refracções que o Sr. Descartes estabeleceu.

Fiquei surpreendido com um acontecimento tão inesperado, que tenho dificuldade em sair do estado de espanto. Repeti diversas vezes as minhas operações algébricas e o resultado foi sempre o mesmo, apesar de a minha demonstração supor que a passagem da luz pelos corpos densos é mais difícil do que pelos rarefeitos, o que creio ser verdadeiro e indiscutível, e que todavia o Sr. Descartes supõe o contrário.

O que devemos concluir de tudo isto? Não bastaria, Senhor, aos amigos do Sr. Descartes eu deixar-lhes a posse livre do seu teorema? Não seria glória bastante ter conhecido os processos da natureza ao primeiro olhar e sem a ajuda de nenhuma demonstração? Cedo-lhe portanto a vitória e o campo de batalha, e contento-me que o Sr. Clerselier me deixe entrar pelo menos na sociedade da prova desta verdade tão importante, e que deve produzir consequências tão admiráveis. 
6. Acrescento mesmo, em favor do seu amigo, que parece que esta grande verdade natural não ousou resistir a este grande génio, e que ela se lhe rendeu à descoberta sem se deixar forçar pela demonstração, a exemplo dessas praças que, ainda que bem guarnecidas e de difícil conquista, não deixam, pela simples reputação dos que as atacam, de render-se sem esperar o disparo dos canhões.

Comunico-vos portanto, Senhor, comunico ao Sr. Clerselier e a todos os amigos do Sr. Descartes que ele não será mais posto em causa pelos geómetras, que não se deve esperar pelas maravilhas que o Sr. Descartes tornou possível saírem das suas lunetas elípticas a hiperbólicas, desde que se possa encontrar operários suficientemente hábeis para as fazer e para as ajustar.

Restaria ainda uma pequena dificuldade que parece resultar da comparação do Sr. Descartes. É que ainda não está esclarecido porque é que a bala que é disparada na água não se aproxima da perpendicularidade, como a luz; mas, além de se poder suspeitar que neste exemplo se mistura a reflexão e a refracção, e que a forma ou a gravidade podem contribuir para a diferença deste movimento, não quero entrar numa matéria puramente física. Seria sobrepor-me a vós, Senhor, que sois mestre na matéria, e invadir o vosso domínio.

Termino portanto depois de vos ter declarado que consinto, se achardes bem, que a reconciliação entre os cartesianos e eu seja publicada nas Academias, [e] depois de o ter solicitado a receber pelo menos o efeito da minha pronta obediência como prova certa e mais que demonstrativa da profunda afeição que vos dedico, Senhor, este muito humilde e muito obediente servidor.

\section{Fermat}

Toulouse, dia $1^{\circ}$ do ano de 1662

P.S. Se continuais a não atribuir um movimento sucessivo à luz, e a sustentar que ele é instantâneo, basta-vos comparar a facilidade ou a fuga e a resistência maior ou menor, à medida que os meios mudam. Porque sendo esta facilidade ou esta resistência maior ou menor em diferentes meios, e isto numa proporção diversa na medida em que os meios diferem mais, elas podem ser consideradas numa certa razão e, por conseguinte, serem objecto de cálculo tal como o tempo do movimento; ou a minha demonstração servirá exactamente para isso. 
Não descrevi completamente a minha operação, e não foi necessário, uma vez que o meu método está impresso em toda a sua extensão no sexto tomo do Cours mathématique de Hérigone e que eu disse o suficiente para ser entendido. Se me ordenais que percorra todos os meandros da análise formal, fá-lo-ei e não terei mesmo grande dificuldade em fazer a demonstração pela composição, quer dizer falando a linguagem de Euclides.

\subsection{Carta $\mathrm{n}^{\circ}$ CXIII (de De Clerselier para Fermat)}

Datada de Sábado, 6 de Maio de 1662 .

Exmo. Senhor.

Não acrediteis que eu pego hoje na pena com intenção de perturbar a paz que propusestes a todos os seguidores de Descartes. As condições em que a propondes são-lhes muito vantajosas e, para mim em particular, muito honrosas para não a aceitarmos; e se todos aqueles que jamais contestaram o seu mestre forem tão sinceros como vós, vê-la-eis estabelecida em breve por todo o lado e com satisfação de todos os partidos.

Havia ainda duas espécies de espíritos a que é preciso satisfazer a propósito da refracção:

Uns, pouco versados nas Matemáticas, que não podiam compreender uma razão extraída da natureza dos movimentos compostos, e vós fizestes-lhes entender o argumento, propondo-lhes um outro princípio aparentemente mais plausível e mais adequado à sua capacidade de entendimento, ou seja, a natureza age sempre pelas vias mais curtas e mais simples;

Outros demasiado agarrados a elas e que não se podiam render às razões puras e simples da metafísica, que, no entanto, é necessariamente preciso juntar com aquelas para lhes dar a força de convicção, e vós retirastes-lhes este obstáculo conduzindo o vosso princípio por um raciocínio puramente geométrico.

E como estas duas espécies de pessoas eram sem dúvida em muito maior número que as outras, não é difícil reconhecer que também mereceis uma parte maior da glória que é devida a uma tão bela e tão importante descoberta.

Não tenho nenhuma inveja de vós, Exmo. Senhor, e prometo-vos dizê-lo em toda a parte e confessar de viva voz que não vi nada de mais engenhoso 
nem melhor encontrado do que a demonstração que fizestes. Permiti-me apenas dizer-vos aqui as razões que um seguidor de Descartes relativamente zeloso poderia alegar para defender a honra e o direito do seu mestre, e para não abrir mão tão depressa de uma coisa sua, nem ceder ao primeiro aceno que lhe façam.

1. O princípio que tomais como fundamento da vossa demonstração, ou seja que a natureza age sempre pelas vias mais curtas e mais simples, é apenas um princípio moral e nada físico, que não é, e que não pode ser, a causa de qualquer efeito da natureza.

Não o é, porque não é este princípio que a faz agir, mas sim a força secreta e a propriedade que há em cada coisa, que nunca é determinada para a este ou aquele efeito por esse princípio, mas pela força que existe em todas as causas que concorrem em conjunto para uma mesma acção, e pela disposição que se encontra realmente em todos os corpos sobre os quais esta força age.

E não o pode ser, senão teríamos de supor que há conhecimento na natureza; aqui, por natureza, entendemos apenas esta ordem e esta lei estabelecida no mundo tal como ele é, que age sem previsão, sem escolha, e por uma determinação necessária.

2. Este mesmo princípio deve causar indecisão na natureza, o não saber a que determinações obedecer, quando tem de passar um raio de luz de um corpo rarefeito para um mais denso. Porque eu pergunto-vos se é verdade que a natureza deve agir sempre pelas vias mais curtas e mais simples, uma vez que a linha recta é sem dúvida mais curta e mais simples que nenhuma outra, quando um raio de luz tem de partir de um ponto dum corpo rarefeito para terminar num ponto de um corpo denso, se não se pode provocar hesitação na natureza, caso queirais que ela aja segundo esse princípio ao seguir a linha recta em vez da quebrada, uma vez que esta resulta mais rápida enquanto a outra resulta mais curta e de mais simples medição? Portanto, quem decidirá sobre isso e quem se pronunciará?

3. Como não é o tempo que se move, também não pode ser ele que determina o movimento, não há nenhuma aparência que possa fazer crer que o tempo mais ou menos breve possa obrigar este corpo a mudar de determinação, visto que não age e não tem nenhum poder sobre ele. Mas como qualquer velocidade e qualquer determinação do movimento deste 
corpo depende da sua força e da disposição da sua força, é muita mais natural e é, na minha opinião, falando como físico, dizer, como faz Descartes, que a velocidade e a determinação deste corpo mudam pela mudança que ocorre na força e na disposição desta força, que são as verdadeiras causas do seu movimento, do que dizer, como o fazeis, que elas mudam pela intenção da natureza de seguir sempre pelo caminho que ela pode percorrer mais rapidamente, intenção que ela não pode ter, uma vez que age sem conhecimento, e que não tem nenhum efeito sobre este corpo.

4. Como só a linha recta é determinada, também é esta linha a única para que a natureza tende em todos os meus movimentos e, apesar de às vezes um corpo pelo seu movimento descrever na realidade uma outra linha, no entanto, se considerarmos, um após outro, todos os pontos que ele percorreu, eles não são mais que os pontos de outras tantas linhas rectas que ele abandona sucessivamente do que os duma linha curva que ele tende a descrever. E ele percorreu-os mais como tais do que outra coisa, visto que, assim que o corpo é deixado livre e abandonado à força que o move em cada ponto, ele seguirá a linha recta à qual este ponto pertence, e de maneira nenhuma a linha curva que descreveu (fig. 101).

Sendo assim, se a questão é levar um raio de luz do ponto $\mathrm{M}$ ao ponto $\mathrm{H}$, é certo que a natureza o enviará directamente pela linha $\mathrm{MH}$, se for possível, e de facto, quando o meio é semelhante e igual, ela nunca falha. Mas quando o meio por onde a luz passa muda de natureza e opõe mais ou menos resistência à sua passagem e ao seu curso, quem fará mudar a sua direcção ao encontrar este meio? De quem podemos suspeitar que seja a causa?

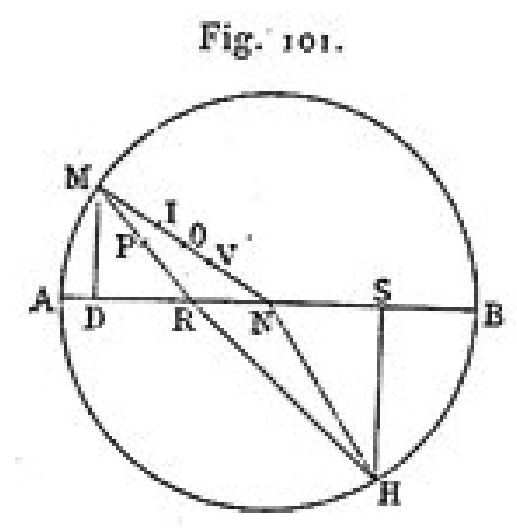


Da brevidade do tempo? De modo nenhum. Porque, quando o raio MN chegou ao ponto $\mathrm{N}$, deve ser-lhe indiferente, seguindo esse princípio, dirigir-se para todos os pontos da circunferência BHA, visto que precisa de tanto tempo para chegar a uns como a outros, e, não podendo este argumento da brevidade do tempo levá-lo para um lugar em vez de para outro, haveria razão para que ele devesse seguir antes em linha recta. Porque, para escolher o ponto $\mathrm{H}$ em vez de outro qualquer, seria necessário supor que este raio MN, que a natureza não pôde enviar para lá sem a tendência indefinida em linha recta, se lembrou que partiu do ponto $\mathrm{M}$ com ordem para procurar, ao encontrar este outro meio, o caminho que pudesse percorrer em menos tempo para a partir daí chegar a $\mathrm{H}$ : o que, em boa verdade, é imaginário e sem nenhum fundamento na Física.

O que fará então mudar a direcção do raio MN (quando chegou ao ponto N) ao encontrar um outro meio senão a razão alegada por Descartes, de que é a mesma força que age e que move o raio MN, ao encontrar uma outra disposição para receber a sua acção neste meio e não no outro; o que muda nela a seu respeito, conforme a direcção deste raio em relação à disposição que ela tem nesse momento? E, porque no ponto de encontro deste outro meio, é apenas a força que leva o raio para baixo, que se ressente da diversidade da recepção da sua acção que existe entre o meio de onde ele sai e aquele em que entra (a que o leva a direito não se ressente porque o meio não se lhe opõe de modo nenhum nesse sentido). A mudança que ocorre no modo de a acção da força que o conduz para baixo é recebida neste ponto de encontro, muda também a direcção do raio e fá-lo desviar do lado a que ele é atraído, segundo a proporção existente nesse momento entre a acção desta força e a da outra. E isso parece-me tão claro que não resta mais nenhum motivo para dúvidas.

5. Se aparentemente é mais razoável acreditar que a luz encontra passagem mais fácil nos corpos rarefeitos do que nos densos, como supondes, baseado na experiência de todos os corpos sensíveis que sem dúvida a têm mais livre nestas espécies de meios, também é, parece-me, mais razoável acreditar que os corpos que entram em meios que oferecem maior resistência à sua passagem do que naqueles de onde eles saem, como admitis que acontece à luz com os corpos densos, se esforçam por se afastar deles e penetram neles o menos que podem. 
O que a experiência confirma: assim, quando uma bala é atirada em diagonal do ar para a água, muito longe de continuar o seu movimento em linha recta, e ainda mais ao continuar a penetração, aproximando-se da perpendicular, ela afasta-se o mais que pode, aproximando-se da superfície. E vós reconhecestes muito bem a força desta objecção, que no entanto classificais de ligeira, mas que não serieis capaz de resolver senão pelo princípio do Sr. Descartes e que destrói completamente o vosso.

Porque, se pelo seu próprio princípio, a bala deve afastar-se da perpendicular, porquê a luz se aproxima dela? E se a bala não segue o vosso princípio, como de facto não segue, porque razão o seguirá a luz? Isso não mostra antes de mais que, num e noutro exemplo, a natureza não age através do vosso princípio?

6. Esta via que achais ser a mais curta porque é a mais rápida, é apenas uma via de erro e de desvio que a natureza não segue, e que não pode ter a intenção de seguir. Porque, como ela é determinada em tudo o que faz, não tende nunca a outra coisa que não seja conduzir os seus movimentos em linha recta.

E assim, se quiserdes que ela tenda antes de $M$ para $H$, ela não pode imaginar traçar um raio dirigido a $\mathrm{N}$, porque este raio por si mesmo não tem nenhuma tendência nesse sentido; mas ela dirigirá o seu raio para $\mathrm{R}$ e, uma vez tendo este raio lá chegado, que é o mais recto, o mais curto e o mais rápido de todos os que podem tender para esse ponto, para ir agora de $\mathrm{R}$ para $\mathrm{H}$, ainda o mais recto, o mais curto e o mais rápido é ir direito a H. E assim, se a natureza agisse pelo vosso próprio princípio, ela deveria ir directamente de $\mathrm{M}$ para $\mathrm{H}$ porque de um lado ela necessita dirigir antes o seu raio para $\mathrm{R}$ e daí o vosso próprio princípio a leva para $\mathrm{H}$.

7. E, apesar de terdes demonstrado claramente, segundo a vossa suposição, que o tempo dos dois raios $\mathrm{MN}$, NH, tomados em conjunto, é mais breve que o de outros dois, quaisquer que sejam, também tomados em conjunto, não é no entanto a razão da brevidade do tempo que leva estes dois raios por estas duas linhas.

Porque seria por acaso possível que um raio que já está no ar, que tem já a sua direcção em linha recta e que não têm nenhuma outra tendência, logo que lhe opõem água ou vidro, imaginasse desviar-se do modo como o faz, pela simples vontade de ir justamente procurar um ponto em que o seu 
movimento composto fosse o mais rápido de todos os que podem lá chegar saindo do seu lugar de partida? Esta razão seria demasiado metafísica para um tema puramente material.

Não se deve antes acreditar, como já o disse, que como é a força do movimento e a sua determinação que conduziram o raio na primeira linha que ele descreveu, sem que o tempo tenha contribuído para isso, é a mudança que ocorre nesta força e nesta determinação que lhe faz tomar o caminho da outra que ele tem de descrever, sem que o tempo contribua para isso, visto que o tempo não produz nada?

8. Afinal a diferença que encontro entre o Sr. Descartes e vós é que vós não provais nada, mas supondes por princípio que a luz passa mais facilmente pelos corpos rarefeitos do que pelos densos; enquanto que o Sr. Descartes prova, e não supõe simplesmente, como dizeis, que a luz passa mais facilmente pelos corpos densos do que pelos rarefeitos.

Porque, considerando o vosso princípio e considerando ainda que a natureza age sempre pelas vias mais curtas e mais rápidas, concluis muito bem que a luz deve seguir o caminho que ela faz na refracção; enquanto o Sr. Descartes, sem supor nada, se serve somente da própria experiência para concluir que a luz passa mais facilmente pelos corpos densos do que pelos rarefeitos, e fornece ao mesmo tempo o meio para medir a proporção com que isso acontece. E, porque julgava que a experiência diária que temos do contrário poderia causar-nos espanto, ele dá a razão física na vigésima terceira página da sua Dióptrica e à qual podemos recorrer.

Mas, se for verdade que a luz passa mais dificilmente pelos corpos rarefeitos do que pelos densos, como parece provar a razão alegada nessa passagem pelo Sr. Descartes, e se também for verdade que a natureza não age sempre pelas vias mais rápidas, como o exemplo da bala que a passagem do ar para a água justifica, adeus a toda a vossa demonstração.

Além disso, como dizeis ter em tempos apresentado as vossas dúvidas ao Sr. Descartes, a ele, dizeis vós, viventi atque sentienti ${ }^{12}$, sem que nem ele nem os seus amigos lhe tenham dado resposta, não poderíamos também dizer que ele lhe respondeu em vida, e os seus amigos depois da sua morte? libi, inquam, viventi, et nisi dicere nefas esset, adderem: et non intelligenti, visto que há quem esteja persuadido de a perceber bem. 
E por fim, como dizeis que a natureza parece ter tido esta deferência e esta amabilidade pelo Sr. Descartes de se render a ele e lhe ter revelado as suas verdades sem se deixar forçar pela demonstração, não podemos nós dizer que vós forçais a Geometria, que tão severa é, em fornecer-vos uma por meio desta dupla falsa posição?

Posto isto deixo aos mais severos e aos mais clarividentes naturalistas o julgamento de quem de vós dois fez a melhor descoberta na causa que ele atribuiu à refracção. Isso não impede que, considerando as coisas de uma outra maneira, eu esteja de acordo convosco em que a natureza age sempre pelas vias mais curtas e mais rápidas. Porque, como ela age apenas pela força que a faz agir necessariamente, e é sempre determinada na sua acção, ela faz sempre tudo o que pode fazer; e assim, qualquer que seja o caminho que ela tome, é sempre o mais curto e o mais rápido possível, consideradas todas as causas que a fizeram agir e que a determinaram.

Tendo-vos deste modo apresentado o que me leva a persistir nos meus primeiros pensamentos, não deixo de me sentir obrigado a render-me e de alguma maneira concordar com os vossos; e, bem longe de lhe disputar a glória de entrar na sociedade da prova duma verdade tão importante, penso ter encontrado um meio que vos deve pôr ambos de acordo, deixando a cada um a parte que lhe pertence.

Parece que, como a luz é a mais nobre produção da natureza, esta a deixa também agir de uma maneira mais regular e mais universal, e que ela fez com que na sua acção tudo o que ela emprega de princípios em todas as outras causas se encontra reunido nesta.

Assim, porque os movimentos dos outros corpos dependem da força que os move e da determinação desta força, a luz, segundo estas leis, ora continua em linha recta ora se desvia dela, aproximando-se ou afastando-se da perpendicular. Mas para vermos também que a natureza age sempre pelas vias mais curtas, era necessário que a luz se comportasse de acordo com esta lei.

O Sr. Descartes mostrou que a luz segue na refracção as leis ordinárias do movimento de todos os corpos, e vós, Exmo. Senhor, mostrastes que, apesar de a luz parecer na refracção tomar um desvio e esquecer-se que deve agir pelas vias mais curtas, ela observa no entanto esta lei com uma exactidão tão grande que não se podia desejar maior. 
E assim pode dizer-se que vós trabalhais conjuntamente com o Sr. Descartes para justificar a natureza nesse aspecto e para explicar o seu processo: ele, com fundamento em razões naturais e comuns a todos os corpos; e vós, Exmo. Senhor, com fundamento em razões matemáticas extraídas da mais pura e fina Geometria.

E mesmo, como esta prova geométrica era a mais difícil de encontrar e de resolver, concedo que tenhais sido superior a ele, e desde já assino e subscrevo uma paz eterna convosco, e não tenho a intenção de mais alguma vez contestar a ineficácia do vosso princípio e da diferença que há entre o vosso e o dele, visto que conduz a uma mesma conclusão e nos ensina uma mesma verdade.

Sou, etc.

\subsection{Carta $\mathrm{n}^{\circ} \mathrm{CXV}$ (de Fermat para De Clerselier)}

Datada de Domingo, 21 de Maio de 1662.

Exmo. Senhor,

As suas duas cartas de seis e treze de $\mathrm{Maio}^{13}$ foram-me entregues ao mesmo tempo. Elas honram-me mais do que eu poderia esperar, e, muito longe de os seus termos latinos me terem chocado, estou persuadido de que, nas vossas conjecturas a respeito da demonstração do Sr. Descartes, não há outras mais verdadeiras em nenhuma passagem das vossas cartas.

Porque se esta demonstração está dentro das regras das demonstrações certas e infalíveis, não há nada de mais verdadeiro do que os que ela não convence, não a entenderem. A qualidade essencial duma demonstração é a de forçar a acreditar, de maneira que os que não sentem esta força, não sentem a própria demonstração, quer dizer que não a entendem.

Portanto eu não atribuo, Exmo. Senhor, senão a um excesso de cortesia e de civilidade esta reparação que os senhores da vossa Assembleia lhe inspiraram, e apresento-lhe os meus muito humildes agradecimentos.

Quanto à questão principal, parece-me que eu disse muitas vezes ao Sr. de la Chambre e a vós que não pretendo nem nunca pretendi ser confidente 
secreto da Natureza. Ela tem caminhos obscuros e ocultos em que nunca tentei penetrar; tinha-lhe apenas oferecido um pequeno recurso de geometria relativamente à refracção, se ela tivesse necessidade dele. Mas uma vez que vós, Exmo. Senhor, me garantis que ela pode resolver os seus assuntos sem essa ajuda e se satisfaz com a maneira de agir que o Sr. Descartes lhe prescreveu, dispenso-vos de boa vontade da minha pretensa conquista de física, e basta-me que me deixais na posse do meu problema de geometria puro e in abstracto, por meio do qual se pode encontrar a trajectória de um objecto móvel que passa por dois meios diferentes e que procura realizar o seu movimento no menor tempo possível.

E não sei mesmo se a maravilha não será maior, supondo-se que interpretei mal o raciocínio da Natureza. Porque podemos nós imaginar algo de mais surpreendente do que aquilo que me aconteceu?

Escrevi, há mais de dez anos ${ }^{14}$, ao Sr. de la Chambre que acreditava que a refracção se devia reduzir a este problema de geometria, e estava então inteiramente persuadido de que a análise deste problema me daria uma proporção diferente da do Sr. Descartes. E, no entanto, ao pegar no problema, que é muito difícil, dez anos depois, encontrei justamente a mesma proporção que o Sr. Descartes.

Se eu disse uma mentira, não terei alguma razão em pretender que é uma dessas mentiras famosas de que se fala no Tasso, como eu já vos escrevi ${ }^{15}$ :

Quando sará ilvero

Sí bello, che si possa a ti proporre?

Aí está, deponho as armas. Permita-me apenas, por favor, que assegure aqui ao Sr. Chanut e ao Sr. abade d'Issoire, seu filho, a minha muito humilde obediência: não tenho a honra de ser conhecido do pai, mas por que razão seria eu o único em toda a Europa a não ter uma total veneração por ele?

Sou, Exmo. Senhor,

Vosso muito humilde e muito obediente servidor,

FERMAT 


\section{Referências}

${ }^{1} \mathrm{O}$ principal legado deste jurista e eminente matemático foram as suas contribuições em diversos domínios das matemáticas: cálculo geométrico e infinitesimal, teoria dos números e teoria da probabilidade.

${ }^{2}$ Em latim Methodus ad disquirendam maximam \& minimam.

${ }^{3}$ Matemático, amigo de Descartes e companheiro deste nas pesquisas sobre Óptica.

${ }^{4}$ No final apresenta-se a sua tradução integral.

${ }^{5}$ Ambos estão publicados no primeiro tomo das CEUVRES DE FERMAT (FERMAT, 1891).

${ }^{6}$ Carta LXXXVI

${ }^{7}$ As cartas para Mersenne XXII e XXIV, para Clerselier XC, XC bis, XCV, XCVII.

${ }^{8}$ Cursus mathematicus tomus quintus, Paris, casa Simeon Piget, MDCXLIV, p.129-130. Axiome V: "As capacidades de penetrar em diversos meios diáfanos, que têm os raios ópticos, aumentam ou diminuem proporcionalmente pela mutação dos meios; e há a mesma proporção entre as capacidades dos raios de incidência e de refracção que entre as pressões que eles sofreriam dos pesos iguais se os suportassem."

${ }^{9}$ Perspectiva horária seu de horographia gnomonica tum theorietica tum practica libri quatuor, Roma, 1648; in-fol., páginas 631-647.

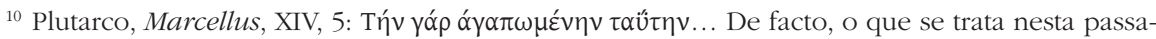
gem, é relativa a Arquimedes, sobre a Mecânica, não sobre a Geometria.

${ }^{11}$ Ver a Analysis ad refractiones, t. I, p. 170 e seg.

${ }^{12}$ Ver acima, páginas 355-356.

${ }^{13}$ Cartas CXIII e CXIV.

${ }^{14}$ Deverá ler-se "seis anos"? A carta LXXXVI não é anterior a 1657.

${ }^{15}$ Ver acima, página 367. 